\title{
BMJ Open Preventive health services implemented by family physicians in Portugal - a cross-sectional study based on two clinical scenarios
}

\author{
Carlos Martins, ${ }^{1}$ Luís Filipe Azevedo, ${ }^{2}$ Cristina Santos, ${ }^{2}$ Luísa Sá, ${ }^{1}$ Paulo Santos, ${ }^{1}$ \\ Maria Couto, ${ }^{1}$ Altamiro Pereira, ${ }^{2}$ Alberto Hespanhol ${ }^{1}$
}

To cite: Martins C, Azevedo LF, Santos C, et al. Preventive health services implemented by family physicians in Portugala cross-sectional study based on two clinical scenarios. BMJ Open 2014;4:e005162. doi:10.1136/bmjopen-2014005162

- Prepublication history for this paper is available online. To view these files please visit the journal online (http://dx.doi.org/10.1136/ bmjopen-2014-005162).

Received 3 March 2014 Revised 24 April 2014 Accepted 28 April 2014

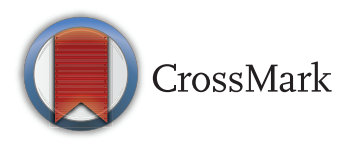

${ }^{1}$ Family Medicine Unit, Social Sciences and Health Department of the Faculty of Medicine of Porto, Porto, Portugal

${ }^{2}$ Information Sciences and Decision on Health Department (CIDES), Faculty of Medicine, Centre for Research in Health Technologies and Information Systems (CINTESIS), University of Porto, Porto, Portugal

Correspondence to Dr Carlos Manuel Martins; carlosmartins20@gmail.com

\section{ABSTRACT}

Objectives: To assess whether Portuguese family physicians perform preventive health services in accordance with scientific evidence, based on the recommendations of the United States Preventive Services Task Force (USPSTF).

Design: Cross-sectional study.

Setting: Primary healthcare, Portuguese National Health Service.

Participants: 255 Portuguese family physicians selected by a stratified cluster sampling design were invited to participate in a computer-assisted telephone survey.

Outcomes: Prevalence of compliance with USPSTF recommendations for screening, given a male and female clinical scenario and a set of proposed medical interventions, including frequency of the intervention and performance in their own daily practice.

Results: A response rate of $95.7 \%$ was obtained $(n=244) .98-100 \%$ of family physicians answered according to the USPSTF recommendations in most interventions. In the male scenario, the lowest concordance was observed in the evaluation of prostate-specific antigen with $37 \%$ of family physicians answering according to the USPSTF recommendations. In the female scenario, the lowest concordance was for cholesterol testing with $2 \%$ of family physicians complying. Family physicians younger than 50 years had significantly better compliance scores than older ones (mean $77 \%$ vs $72 \%$; $p<0.001$ ).

Conclusions: We found a high degree of agreement with USPSTF recommendations among Portuguese family physicians. However, we also found results suggesting excessive use of some medical interventions, raising concerns related to possible harm associated with overdiagnosis and overtreatment.

\section{INTRODUCTION}

Concern exists about the implementation of preventive services of proven benefit in primary care, but there is also concern about the excessive use of preventive services and the harm that may arise from this. This study

\section{Strengths and limitations of this study}

Simple design of the survey based on two clinical scenarios.

- The high response rate.

- Evidence that physicians know the preventive services they should apply, but have difficulty applying them with the appropriate frequency.

- Stratified cluster sampling design, which may have led to some misrepresentation.

- Self-report bias.

focuses on the application of preventive services by family physicians in Portugal.

From a historical perspective, the development of preventive medicine and the application of preventive healthcare services have a close connection with the genesis of the 'periodic health examination'. A periodic health examination is the assessment of health status carried out at predetermined intervals, for example, yearly, usually following a protocol with a set of structured questions and a set of predetermined laboratory tests. ${ }^{1}$ One of the first recommendations for the implementation of a periodic health examination dates from 1922, when the American Medical Association proposed an annual medical examination for all adults, which included a battery of laboratory tests. ${ }^{2}$ In the 1970s, Frame and Carlson ${ }^{3}$ conducted a critical review of the effectiveness of preventive health services applied routinely at the periodic health examination and suggested that the selection of preventive health services should be carried out according to their effectiveness and specifically adjusted for the age and sex of each patient. ${ }^{2}$ This critical analysis has contributed to the debate of the effectiveness of some tests that were being generally applied with preventive intent. ${ }^{4}$ It was in this context that, in 1976, 
the Canadian Task Force on the Periodic Health Examination, now called Canadian Task Force on Preventive Health Care, was created in order to evaluate the scientific evidence and make recommendations on preventive health services that should be implemented in the periodic health examination carried out on asymptomatic adults. ${ }^{5}$ With similar objectives, the United States Preventive Services Task Force (USPSTF) appeared in $1984 .{ }^{6}$ The appearance of these two task forces coincided with the emergence of evidence-based medicine, which allowed for the incorporation of new methods of bibliographic review. These new methods allowed for the publication of recommendations for preventive interventions according to a scale based on the levels of scientific evidence and degrees of recommendation. ${ }^{7-9}$ Since then, the recommendations have been updated, adopted and adapted by various work groups. ${ }^{10} 11$ Thus, clinicians have obtained a set of practical tools that may guide them, based on the best scientific evidence, in the selection of preventive interventions to be proposed to their patients, which may constitute a significant advance in the quality of performance of preventive medicine.

However, as evidence-based medicine, the implementation of the recommendations of preventive interventions always involves the right integration of three key components: the evidence resulting from the best scientific research, clinical expertise and the personal values of the patient. ${ }^{12}$ This integration is not linear and depends on many factors, which may contribute heterogeneity in the way preventive interventions are applied. Several barriers to the implementation of preventive interventions have been described: the shortage of time, the excess of tasks, the absence of financial compensation, heterogeneity of recommendations, reduced patient compliance and the clinicians' feelings of lack of self-efficacy. ${ }^{13-17}$

Several studies indicate that health professionals, despite having updated, evidence-based recommendations, continue to implement interventions whose effectiveness is not proven. A cross-sectional study conducted in the USA, which analysed data from 6 years of routine office visits for preventive health exams, concluded that in $43 \%$ of consultations, at least one non-recommended test was ordered. ${ }^{18}$ Another study, involving 2082 family physicians, and conducted in several European countries, showed a clear gap between clinical practice and evidence-based recommendations: $40.8 \%$ of physicians reported usually ordering X-rays for lung cancer screening in asymptomatic adults, whereas only $18.9 \%$ of physicians adequately ordered the colorectal cancer screening. ${ }^{13}$

Technological developments in the second half of the 20th century, particularly in the field of diagnostic tests, contributed to the growing number of interventions with supposed preventive intent available to health professionals and the public. Some of these interventions involve high costs and can contribute significantly to the difficulties involved in sustaining health systems. ${ }^{18-20}$ In recent years, there has been growing evidence that there may also be significant harm to patients from inappropriately delivered preventive interventions, due to eventual overdiagnosis that may lead to overtreatment. ${ }^{21-24}$ In this context, it is important to know how primary care physicians are delivering preventive health services.

In Portugal, we now have access to data collected by the National Service regarding some preventive interventions conducted as part of pay for performance schemes. Initial results appear to be promising. ${ }^{25}$

The aim of this study is to assess whether Portuguese family physicians are performing preventive health services in accordance with the scientific evidence, based on the recommendations of the USPSTF.

\section{METHODS}

\section{Study design}

A cross-sectional study was conducted in a representative sample of Portuguese family physicians, using computerassisted telephone interviews for data collection.

\section{Setting}

The defined target population was the population of Portuguese family physicians working in the National Health Service. Data collection occurred between 1 April 2012 and 12 October 2012.

\section{Selection criteria}

All medical doctors working as family physicians in National Health Service primary care health units were eligible. There were no exclusion criteria.

\section{Survey sampling methods and sample size}

To obtain a representative sample of Portuguese family physicians, given that no official database of family physicians working at the National Health Service was available, a stratified cluster sampling design was used. The Portuguese National Health Service is administratively divided into five regional health administrations. We considered each regional health administration as a stratum and randomly selected a proportion of the primary healthcare units for each regional administration. Each primary healthcare unit was a cluster, and we randomly selected one-third of the family physicians working at each unit.

According to the Portuguese National Institute of Statistics, in 2010, there were 5273 family physicians working in the National Health Service. ${ }^{26}$ According to the list of primary healthcare units provided by the Ministry of Health, there were 902 units (an average of 5.85 family physicians per unit).

To determine the sample size, the recommended protocol for this type of sampling designs was used, ${ }^{26}$ according to the following steps:

1. Setting the desired precision of the estimates. 
2. Setting the number of family physicians (secondary sampling units) to be selected in each primary healthcare unit ( primary sampling units or 'clusters').

3. Setting the number of primary healthcare units to be selected for the sample (primary sampling units or 'clusters').

Regarding the required precision for the estimation of proportions, we decided that the margin of error (the half-width of the $95 \% \mathrm{CI}$ ) required should be at most $7.5 \%$.

The definition of the number of family physicians to be selected in each primary healthcare unit took into account the minimisation of the variance of the desired estimates for a given fixed cost of the sampling procedures. ${ }^{27}$ We have decided to select on average two family physicians in each primary healthcare unit, corresponding to nearly one-third of the family physicians in each primary healthcare unit.

Finally, to define the number of primary healthcare units to be selected for the sample, we have followed an approximation method based on an estimate of the design effect. ${ }^{27}$ According to our calculations, the size of our sample should be between 174 and 301 family physicians. Given some financial constraints, the final sample size defined for this study was 180 family physicians distributed among 90 primary care health units, proportionately and randomly selected for each regional health administration, as shown in table 1 .

\section{Quality control}

The interviewers had extensive experience in computerassisted telephone interviewing and were adequately trained and prepared for the application of the study questionnaire. A pilot test was run in order to assess the time required to complete the questionnaire and to assess questionnaire language and comprehension issues. A data collection supervisor supervised all interviews. Additionally, at least a study coordinator randomly supervised $20 \%$ of the interviews.

\section{Instruments and methods for data collection}

In order to achieve the best response rate and to avoid selection bias, we wrote to all family physicians working at the selected primary healthcare units by email with information about the study, ethical and administrative authorisations, and information about possible future telephone contact. At the same time, we sent emails to Portuguese family physician mailing groups informing them about this study.

First telephone contact was made to the family physicians selected at each primary healthcare unit asking for consent and preferred days and times for performing the interview. Since contact was made by telephone, only oral consent was obtained. Data collection was carried out between 29 March 2012 and 12 October 2012, using computer-assisted telephone interviews. A structured questionnaire containing three sections was used: (1) an introductory section presenting the study aims and consent form, (2) the research instrument and (3) sociodemographic data including age, gender, practice location (urban or rural as defined by the participant) and professional qualification.

In the research section, the participants were asked to answer three questions regarding two clinical scenarios. Family physicians were asked to consider a 52-year-old male patient in a first consultation for a routine health check. The patient had not undergone any previous medical tests and had no personal or family history of serious illness or other risk factors.

The three questions asked were:

A. Based on the scientific evidence and current recommendations, do you think you should perform the following medical interventions on this patient?

B. Do you usually perform, in your clinical practice, these interventions in patients with the same characteristics as the patient presented in this clinical scenario?

C. If you do so, how often do you perform this intervention, assuming that the previous results are normal?

Question (C) was only posed when the answer to question (B) was 'yes'.

These three questions referred to the following interventions: serum cholesterol, blood pressure measurement, fasting glucose levels for diabetes screening, faecal occult blood test, prostate-specific antigen (PSA), digital rectal examination, chest X-ray and assessment of tetanus immunisation status. Additionally, questions (A) and (B) also referred to the following interventions:

Table 1 Primary healthcare units by regional health administrations in the Portuguese National Health Service sampled for the study of preventive health services implemented by primary healthcare physicians

\begin{tabular}{llc}
\hline & $\begin{array}{l}\text { Number of primary healthcare } \\
\text { units in the Portuguese } \\
\text { National Health Service }\end{array}$ & $\begin{array}{l}\text { Number of primary } \\
\text { healthcare units (clusters) } \\
\text { selected for our sample }\end{array}$ \\
\hline Northern regional health administration & 381 & 38 \\
Centre regional health administration & 65 & 6 \\
Lisbon and Tagus Valley regional health administration & 380 & 38 \\
Alentejo regional health administration & 57 & 6 \\
Algarve regional health administration & 19 & 2 \\
Total & 902 & 90 \\
\hline
\end{tabular}


questions about smoking habits, smoking cessation advice to smokers, questions about alcohol consumption, advice to reduce alcohol consumption to those with risky drinking behaviours, calculation of body mass index, advice to obese or overweight patients to lose weight, questions about physical activity and advice to sedentary patients to exercise regularly.

In the second clinical scenario, family physicians were asked to consider a similar situation with a 52-year-old female patient in a first consultation for a routine health check. The patient had not had any previous medical tests and had no personal or family history of serious illness or other risk factors. The three questions were identical to those in the first clinical scenario, but the medical interventions were slightly different. Questions (A), (B) and (C) referred to the following interventions: serum cholesterol, blood pressure measurement, fasting glucose levels for diabetes screening, faecal occult blood test, mammography, clinical breast exam, cervical cytology and questions about tetanus immunisation status. Additionally, questions (A) and (B) also referred to the following interventions: questions about smoking habits, smoking cessation advice to smokers, questions about alcohol consumption, advice to reduce alcohol consumption to those with risky drinking behaviours, calculation of body mass index, advice to obese or overweight patients to lose weight, questions about physical activity and advice to sedentary patients to exercise regularly.

This main research section of the questionnaire was an authorised adaptation of a previous questionnaire applied to European general practitioners. ${ }^{13}$

\section{Statistical analysis}

Statistical analysis was performed using the Statistical Package for the Social Sciences V.21.0 for Windows (SPSS). Descriptive statistics are presented as absolute and relative frequencies and as median and maximum/ minimum values for periodicity of application of health services in months. For each investigated preventive health intervention, we compared the physicians' opinions regarding the use of the interventions and their actual use, using the McNemar test. We also compared the percentage of family physicians believing they should perform each intervention between male and female physicians, between urban and rural physicians and between physicians older or younger than 50 years of age, using $\chi^{2}$ tests. Considering the USPSTF recommendations, including the periodicity of the interventions, a score from 0 to 100 was calculated, for each family physician, where 0 corresponds to no concordance with any of the USPSTF recommendations and 100 corresponds to complete concordance. For example, if a physician answered 14 out of the 16 suggested preventive activities correctly, he would receive a score of (14/ $16 \times 100)$ 87.5. We compare this score between female and male physicians, between urban and rural physicians and between physicians older or younger than 50 years of age, using an independent sample t test. A multivariate logistical regression model was used to assess independent factors associated with the prevalence of physicians considering whether they should perform each preventive health intervention. Whenever statistical hypothesis testing was used, a significance level of $5 \%$ was considered.

\section{Ethical considerations}

All participants provided their verbal informed consent at the beginning of the telephone interview. The ethics committee agreed that we dispense with a written document of consent because interviews were conducted by telephone, without the physical presence of participants. Participants were informed about the estimated duration of the interview, confidentiality was assured and the voluntary nature of their participation was emphasised. Participants were informed that they could interrupt their participation at any time during the interview. The interviews were not recorded and participants did not receive any kind of compensation. To standardise the process of obtaining informed consent, the interviewers were trained to read the text of the informed consent form. This procedure of obtaining consent was approved by the Northern Regional Health Administration Ethics Committee for Health.

\section{RESULTS}

Out of a total of 255 randomly selected family physicians invited, 244 agreed to participate, for a response rate of 95.7\%. They worked in 90 different Portuguese National Health Service primary healthcare units. The mean duration of the interview was $15 \mathrm{~min}$. Most of the participants were between 30 and 59 years old with 149 women and 95 men. In table 2, we present the demographic description of the study sample.

In the male clinical scenario (table 3), almost all (98$100 \%$ ) of the family physicians considered that they should perform the following preventive interventions: serum cholesterol, blood pressure measurement, fasting glucose test, questions about tetanus immunisation status, questions about smoking habits, smoking cessation advice to smokers, questions about alcohol consumption, advice to reduce alcohol consumption to those with risky drinking behaviours, calculation of body mass index, advice to obese or overweight patients to lose weight, questions about physical activity and advice to sedentary patients to exercise regularly. Fewer family physicians considered that they should perform faecal occult blood tests (84\% of physicians), evaluation of PSA $(63 \%)$ and the digital rectal examination (66\%). Only $32 \%$ of the family physicians considered that they should perform the chest X-ray as a screening procedure in a healthy patient.

There was a statistically significant difference between what family physicians said they should perform and what they said they perform regularly in clinical practice 
Table 2 Demographic characteristics of the study sample in the study of preventive health services implemented by Portuguese primary healthcare physicians $(n=244)$

n $(\%)$

\section{Age}

20-29

30-39

40-49

$50-59$

60-69

Gender

Male

Female

Regional health administration

North

Centre

Lisbon and Tagus Valley

Alentejo

Algarve

Workplace

Urban

Rural

Professional qualifications

Specialist in family medicine/general practice 241

Non-specialist working as a family doctor

$1 \quad(1)$

33

44

155

11

95

$149(61)$

82 (34)

$17 \quad(7)$

$130 \quad(53)$

11 (4)

4

Specialist in family medicine/general practice, years

Less than 2

For 2-10

157

87

More than 10

201

)

)

)

)

(4)

)

(83)

for two interventions: digital rectal examination and assessment of tetanus immunisation status (table 3). We did not observe any statistically significant difference between female and male family physicians (table 3). Comparing urban family physicians with rural family physicians, we observed a statistically significant difference in two interventions: chest X-ray and assessment of tetanus immunisation status (table 3). Comparing family physicians younger than 50 with family physicians 50 or older, we found a statistically significant difference in three interventions: evaluation of PSA, digital rectal examination and chest X-ray (table 3).

In a multivariate model, only an age over 50 $(\mathrm{OR}=2.642,95 \% \mathrm{CI}(1.357$ to 5.144$))$ and a rural work setting (OR=2.120, 95\% CI (1.197 to 3.756$))$ were independent factors associated with a higher prevalence of physicians who considered that they should perform the chest X-ray.

For the female clinical scenario, almost all of the family physicians (98-100\%) considered that they should perform the following preventive interventions: serum cholesterol, blood pressure measurement, fasting glucose test, mammography, cervicovaginal cytology, tetanus immunisation status verification, questions about smoking habits, smoking cessation advice to smokers, questions about alcohol consumption, advice to reduce alcohol consumption to those with risky drinking behaviours, calculation of body mass index, advice to obese or overweight patients to lose weight, questions about physical activity and advice to sedentary patients to exercise regularly. Fewer physicians considered that they should perform clinical breast examination $(96 \%)$ and the faecal occult blood test $(83 \%)$. Only $34 \%$ of the family physicians considered that they should perform the chest X-ray.

In the female scenario we found a statistically significant difference between what family physicians said they should perform and what they said they perform regularly in clinical practice for three interventions: the clinical breast exam, the chest X-ray and the assessment of tetanus immunisation status. More physicians answered that they should perform these interventions than the number of physicians who said they perform these interventions regularly (table 4 ). Comparing female family physicians with male family physicians, urban family physicians with rural family physicians and family physicians younger than 50 with family physicians 50 or older, we found a statistically significant difference for only one intervention: the chest X-ray (table 4).

In a multivariate model, only age over $50(\mathrm{OR}=2.973$, 95\% CI (1.512 to 5.707)) and a rural work setting $(\mathrm{OR}=2.126,95 \% \mathrm{CI}(1.202$ to 3.762$))$ were independent factors associated with a higher prevalence of physicians who considered that they should perform the chest X-ray.

With regard to the frequency of preventive interventions in the male clinical scenario (table 5), over $90 \%$ answered that they perform cholesterol testing, blood pressure measurement, fasting glucose test, evaluations of PSA and digital rectal examinations periodically, with a median 12-month interval. Among family physicians who said that they perform chest X-rays, $42 \%$ answered that they perform this procedure periodically, with a median 24-month interval (minimum 12 months; maximum 60 months). In the female clinical scenario, the results are quite similar to those obtained in the male scenario for non-gender-specific interventions. Among family physicians who said that they perform mammography, clinical breast exam and cervical cytology, 99-100\% answered that they perform these tests periodically, with a median 24-month interval for mammography and a 12-month interval for clinical breast exams and cervical cytology.

Most family physicians (98-100\%) answered in accordance with the USPSTF recommendations for most interventions suggested (table 6) excluding those interventions for which the USPSTF considers there to be insufficient evidence (table 7). In the male clinical scenario, we find the lowest concordance in the evaluation of PSA. Only 37\% of family physicians answered according to the USPSTF recommendation. In the female clinical scenario, we found the lowest concordance for the cholesterol testing. Only $2 \%$ of family physicians answered according to the USPSTF recommendation, which recommends screening women aged 45 and older for lipid disorders only if they have an 
Table 3 Proportion of family physicians stating that they should perform and normally use the proposed preventive services in the male patient clinical scenario ( $\mathrm{n}=244$ )

\begin{tabular}{|c|c|c|c|c|c|c|c|c|c|c|c|c|c|c|c|c|c|c|c|c|}
\hline & \multirow{2}{*}{\multicolumn{2}{|c|}{$\begin{array}{l}\text { Yes, I } \\
\text { should } \\
\text { perform } \\
\text { it }\end{array}$}} & \multirow{2}{*}{\multicolumn{2}{|c|}{$\begin{array}{l}\text { Yes, I } \\
\text { usually } \\
\text { perform } \\
\text { it }\end{array}$}} & \multirow[b]{3}{*}{ p Value } & \multicolumn{4}{|c|}{$\begin{array}{l}\text { Yes, I should } \\
\text { perform it }\end{array}$} & \multirow[b]{3}{*}{ p Value } & \multicolumn{4}{|c|}{$\begin{array}{l}\text { Yes, I should } \\
\text { perform it }\end{array}$} & \multirow[b]{3}{*}{ p Value } & \multicolumn{4}{|c|}{$\begin{array}{l}\text { Yes, I should } \\
\text { perform it }\end{array}$} & \multirow[b]{3}{*}{ p Value } \\
\hline & & & & & & \multicolumn{2}{|c|}{$\begin{array}{l}\text { Female } \\
\text { GPs }\end{array}$} & \multicolumn{2}{|c|}{$\begin{array}{l}\text { Male } \\
\text { GPs }\end{array}$} & & \multicolumn{2}{|c|}{$\begin{array}{l}\text { Urban } \\
\text { GPs }\end{array}$} & \multicolumn{2}{|c|}{$\begin{array}{l}\text { Rural } \\
\text { GPs }\end{array}$} & & \multicolumn{2}{|c|}{$\begin{array}{l}\text { GPs } \\
<50 \text { years }\end{array}$} & \multicolumn{2}{|c|}{$\begin{array}{l}\text { GPs } \\
\geq 50 \text { years }\end{array}$} & \\
\hline & $\mathbf{n}$ & $(\%)$ & $\mathrm{n}$ & $(\%)$ & & $\mathrm{n}$ & $(\%)$ & $\mathrm{n}$ & $(\%)$ & & $\mathrm{n}$ & $(\%)$ & $\mathbf{n}$ & $(\%)$ & & $\mathrm{n}$ & $(\%)$ & $\mathrm{n}$ & $(\%)$ & \\
\hline Chol & 240 & (98) & 242 & (99) & .500 & 148 & (99) & 92 & (97) & 0.302 & 155 & (99) & 85 & (98) & 0.618 & 77 & (99) & 163 & (98) & 1.000 \\
\hline Blood pressure & 244 & $(100)$ & 244 & $(100)$ & $-^{*}$ & 149 & $(100)$ & 95 & $(100)$ & - & 157 & $(100)$ & 87 & $(100)$ & - & 78 & $(100)$ & 166 & $(100)$ & - \\
\hline Fasting glucose & 240 & $(98)$ & 241 & $(99)$ & 1.000 & 148 & (99) & 92 & (97) & 0.302 & 156 & (99) & 84 & $(97)$ & 0.131 & 78 & $(100)$ & 162 & $(98)$ & 0.309 \\
\hline FOBT & 205 & (84) & 202 & (83) & 0.549 & 128 & (86) & 77 & (81) & 0.313 & 137 & (87) & 68 & (78) & 0.063 & 64 & (82) & 141 & (85) & 0.566 \\
\hline PSA & 153 & (63) & 158 & $(65)$ & 0.359 & 91 & (61) & 62 & $(65)$ & 0.509 & 99 & (63) & 54 & $(62)$ & 0.878 & 38 & (49) & 115 & (69) & 0.002 \\
\hline Digital rectal examination & 161 & (66) & 143 & (59) & 0.001 & 100 & (67) & 61 & (64) & 0.641 & 103 & (66) & 58 & (67) & 0.867 & 44 & (56) & 117 & (70) & 0.030 \\
\hline Chest X-ray & 79 & (32) & 76 & (31) & 0.664 & 42 & (28) & 37 & (39) & 0.080 & 42 & (27) & 37 & (43) & 0.012 & 15 & (19) & 64 & (39) & 0.003 \\
\hline Assessment of tetanus immunisation & 241 & (99) & 224 & (92) & $<0.001$ & 147 & $(99)$ & 94 & (99) & 1.000 & 157 & $(100)$ & 84 & $(97)$ & 0.044 & 77 & (99) & 164 & (99) & 1.000 \\
\hline Inquiry about smoking habits & 244 & $(100)$ & 244 & $(100)$ & - & 149 & $(100)$ & 95 & $(100)$ & - & 157 & $(100)$ & 87 & $(100)$ & - & 78 & $(100)$ & 166 & $(100)$ & - \\
\hline Advice to quit smoking & 240 & $(98)$ & 242 & (99) & 0.500 & 148 & $(99)$ & 92 & (97) & 0.302 & 154 & $(98)$ & 86 & $(99)$ & 1.000 & 77 & $(99)$ & 163 & $(98)$ & 1.000 \\
\hline Inquiry about alcohol habits & 243 & $(100)$ & 243 & $(100)$ & 1.000 & 149 & $(100)$ & 94 & (99) & 0.389 & 157 & $(100)$ & 86 & (99) & 0.357 & 78 & $(100)$ & 165 & (99) & 1.000 \\
\hline Advice to modify risky drinking habits & 244 & $(100)$ & 244 & $(100)$ & - & 149 & $(100)$ & 95 & $(100)$ & - & 157 & $(100)$ & 87 & $(100)$ & - & 78 & $(100)$ & 166 & $(100)$ & - \\
\hline Body mass index calculation & 243 & $(100)$ & 243 & $(100)$ & 1.000 & 149 & $(100)$ & 94 & (99) & 0.389 & 157 & $(100)$ & 86 & (99) & 0.357 & 78 & $(100)$ & 165 & (99) & 1.000 \\
\hline $\begin{array}{l}\text { Weight loss advice to overweight } \\
\text { patients }\end{array}$ & 244 & $(100)$ & 244 & $(100)$ & - & 149 & $(100)$ & 95 & $(100)$ & - & 157 & $(100)$ & 87 & $(100)$ & - & 78 & $(100)$ & 166 & $(100)$ & - \\
\hline Inquiry about physical activity & 244 & $(100)$ & 244 & $(100)$ & - & 149 & $(100)$ & 95 & $(100)$ & - & 157 & $(100)$ & 87 & $(100)$ & - & 78 & $(100)$ & 166 & $(100)$ & - \\
\hline Activity advice to sedentary patients & 244 & $(100)$ & 244 & $(100)$ & - & 149 & $(100)$ & 95 & $(100)$ & - & 157 & $(100)$ & 87 & $(100)$ & - & 78 & $(100)$ & 166 & $(100)$ & - \\
\hline
\end{tabular}

$p$ Values $<0.05$ are presented italic.

${ }^{*} \mathrm{p}$ Values are not presented when results of the compared terms where equal.

GPs, general practitioners; FOBT, faecal occult blood test; PSA, prostate-specific antigen. 
Table 4 Proportion of family physicians stating that they should perform and normally use the proposed preventive services in the female patient clinical scenario ( $\mathrm{n}=244$ )

\begin{tabular}{|c|c|c|c|c|c|c|c|c|c|c|c|c|c|c|c|c|c|c|c|c|}
\hline & \multirow{2}{*}{\multicolumn{2}{|c|}{$\begin{array}{l}\text { Yes, I } \\
\text { should } \\
\text { perform } \\
\text { it }\end{array}$}} & \multirow{2}{*}{\multicolumn{2}{|c|}{$\begin{array}{l}\text { Yes, I } \\
\text { perform } \\
\text { it }\end{array}$}} & \multirow[b]{3}{*}{ p Value } & \multicolumn{4}{|c|}{$\begin{array}{l}\text { Yes, I should } \\
\text { perform it }\end{array}$} & \multirow[b]{3}{*}{ p Value } & \multicolumn{4}{|c|}{$\begin{array}{l}\text { Yes, I should } \\
\text { perform it }\end{array}$} & \multirow[b]{3}{*}{ p Value } & \multicolumn{4}{|c|}{$\begin{array}{l}\text { Yes, I should } \\
\text { perform it }\end{array}$} & \multirow[b]{3}{*}{ p Value } \\
\hline & & & & & & \multicolumn{2}{|c|}{$\begin{array}{l}\text { Female } \\
\text { GPs }\end{array}$} & \multicolumn{2}{|c|}{$\begin{array}{l}\text { Male } \\
\text { GPs }\end{array}$} & & \multicolumn{2}{|c|}{$\begin{array}{l}\text { Urban } \\
\text { GPs }\end{array}$} & \multicolumn{2}{|c|}{$\begin{array}{l}\text { Rural } \\
\text { GPs }\end{array}$} & & \multicolumn{2}{|c|}{$\begin{array}{l}\text { GPs } \\
<50 \text { years }\end{array}$} & \multicolumn{2}{|c|}{$\begin{array}{l}\text { GPs } \\
\geq 50 \text { years }\end{array}$} & \\
\hline & $\bar{n}$ & $(\%)$ & $\bar{n}$ & $(\%)$ & & $\bar{n}$ & (\%) & $\bar{n}$ & $(\%)$ & & $\bar{n}$ & $(\%)$ & $\overline{\mathbf{n}}$ & (\%) & & $\bar{n}$ & $(\%)$ & $\bar{n}$ & $(\%)$ & \\
\hline Cholesterol & 240 & (98) & 241 & (99) & 1.000 & 148 & (99) & 92 & (97) & 0.302 & 155 & (99) & 85 & (98) & 0.618 & 77 & (99) & 163 & (98) & 1.000 \\
\hline Blood pressure & 244 & $(100)$ & 243 & $(100)$ & $-^{\star}$ & 149 & $(100)$ & 95 & $(100)$ & - & 157 & (100) & 87 & $(100)$ & - & 78 & $(100)$ & 166 & $(100)$ & - \\
\hline Fasting glucose & 240 & (98) & 242 & (99) & 0.500 & 148 & (99) & 92 & $(97)$ & 0.302 & 156 & (99) & 84 & (97) & 0.131 & 78 & $(100)$ & 162 & (98) & 0.309 \\
\hline FOBT & 203 & (83) & 198 & (81) & 0.063 & 128 & (86) & 75 & (79) & 0.156 & 135 & (86) & 68 & (78) & 0.117 & 63 & $(81)$ & 140 & (84) & 0.487 \\
\hline Mammography & 244 & $(100)$ & 242 & (99) & - & 149 & $(100)$ & 95 & $(100)$ & - & 157 & $(100)$ & 87 & $(100)$ & - & 78 & $(100)$ & 166 & $(100)$ & - \\
\hline Clinical breast exam & 234 & (96) & 221 & (91) & $<0.001$ & 144 & (97) & 90 & $(95)$ & 0.518 & 149 & (95) & 85 & (98) & 0.291 & 72 & $(92)$ & 162 & $(98)$ & 0.079 \\
\hline Cervical cytology & 244 & $(100)$ & 244 & $(100)$ & - & 149 & $(100)$ & 95 & $(100)$ & - & 157 & $(100)$ & 87 & $(100)$ & - & 78 & $(100)$ & 166 & $(100)$ & - \\
\hline Chest X-ray & 84 & (34) & 73 & (30) & 0.027 & 43 & $(29)$ & 41 & (43) & 0.022 & 45 & (29) & 39 & $(45)$ & 0.011 & 15 & (19) & 69 & $(42)$ & 0.001 \\
\hline Assessment of Tetanus immunisation & 242 & (99) & 223 & (91) & $<0.001$ & 148 & (99) & 94 & (99) & 1.000 & 157 & $(100)$ & 85 & (98) & 0.126 & 78 & $(100)$ & 164 & (99) & 1.000 \\
\hline Inquiry about smoking habits & 244 & $(100)$ & 244 & $(100)$ & - & 149 & $(100)$ & 95 & $(100)$ & - & 157 & (100) & 87 & $(100)$ & - & 78 & $(100)$ & 166 & $(100)$ & - \\
\hline Advice to quit smoking & 240 & (98) & 242 & (99) & 0.500 & 148 & (99) & 92 & $(97)$ & 0.302 & 154 & (98) & 86 & (99) & 1.000 & 77 & (99) & 163 & (98) & 1.000 \\
\hline Inquiry about alcohol habits & 243 & $(100)$ & 243 & $(100)$ & 1.000 & 149 & $(100)$ & 94 & (99) & 0.389 & 157 & $(100)$ & 86 & (99) & 0.357 & 78 & $(100)$ & 165 & (99) & 1.000 \\
\hline Advice to modify risky drinking habits & 244 & $(100)$ & 244 & $(100)$ & - & 149 & $(100)$ & 95 & $(100)$ & - & 157 & $(100)$ & 87 & $(100)$ & - & 78 & $(100)$ & 166 & $(100)$ & - \\
\hline Body mass index calculation & 243 & $(100)$ & 243 & $(100)$ & 1.000 & 149 & (100) & 94 & (99) & 0.389 & 157 & $(100)$ & 86 & (99) & 0.357 & 78 & $(100)$ & 165 & (99) & 1.000 \\
\hline $\begin{array}{l}\text { Weight loss advice to overweight } \\
\text { patients }\end{array}$ & 244 & (100) & 244 & $(100)$ & - & 149 & $(100)$ & 95 & $(100)$ & - & 157 & $(100)$ & 87 & $(100)$ & - & 78 & $(100)$ & 166 & $(100)$ & - \\
\hline Inquiry about physical activity & 244 & $(100)$ & 244 & $(100)$ & - & 149 & $(100)$ & 95 & $(100)$ & - & 157 & $(100)$ & 87 & $(100)$ & - & 78 & $(100)$ & 166 & $(100)$ & - \\
\hline Activity advice to sedentary patients & 244 & $(100)$ & 244 & $(100)$ & & 149 & $(100)$ & 95 & $(100)$ & - & 157 & $(100)$ & 87 & $(100)$ & - & 78 & $(100)$ & 166 & $(100)$ & - \\
\hline
\end{tabular}

p Values $<0.05$ are presented italic.

${ }^{*} \mathrm{p}$ Values are not presented when results of the compared terms are equal.

fGPs, general practitioners; FOBT, faecal occult blood test. 
Table 5 Frequency of preventive interventions (calculated for each intervention based on the number of family physicians who said they perform it)

\begin{tabular}{|c|c|c|c|c|c|c|}
\hline & \multirow{2}{*}{$\begin{array}{l}\text { Yes, } \\
\text { I perform } \\
\text { it } \\
\mathrm{N}\end{array}$} & \multicolumn{2}{|c|}{$\begin{array}{l}\text { Health services } \\
\text { periodically } \\
\text { applied }\end{array}$} & \multicolumn{3}{|c|}{ Periodicity in months } \\
\hline & & $\bar{n}$ & $\mathrm{n} / \mathrm{N}(\%)$ & Minimum & Median & Maximum \\
\hline \multicolumn{7}{|l|}{ Male clinical scenario } \\
\hline Cholesterol & 242 & 239 & (99) & 6 & 12 & 60 \\
\hline Blood pressure & 244 & 242 & (99) & 3 & 12 & 36 \\
\hline Fasting glucose & 241 & 239 & (99) & 6 & 12 & 60 \\
\hline FOBT & 202 & 189 & (94) & 5 & 24 & 60 \\
\hline Digital rectal examination & 143 & 134 & (94) & 12 & 12 & 60 \\
\hline Evaluation of PSA & 158 & 147 & (93) & 12 & 12 & 60 \\
\hline Tetanus immunisation status verification & 224 & 209 & (93) & 12 & 120 & 120 \\
\hline Chest X-ray & 76 & 32 & (42) & 12 & 24 & 60 \\
\hline \multicolumn{7}{|l|}{ Female clinical scenario } \\
\hline Fasting glucose & 242 & 242 & $(100)$ & 6 & 12 & 60 \\
\hline Mammography & 242 & 242 & $(100)$ & 2 & 24 & 60 \\
\hline Cervical cytology & 244 & 243 & $(100)$ & 12 & 12 & 36 \\
\hline Cholesterol & 241 & 237 & $(98)$ & 6 & 12 & 60 \\
\hline Blood pressure & 243 & 238 & (98) & 1 & 12 & 36 \\
\hline FOBT & 198 & 186 & (94) & 12 & 24 & 60 \\
\hline Clinical breast exam & 221 & 218 & (99) & 6 & 12 & 24 \\
\hline Chest X-ray & 73 & 30 & (41) & 12 & 24 & 60 \\
\hline Assessment of tetanus immunisation & 223 & 211 & (95) & 12 & 120 & 120 \\
\hline
\end{tabular}

increased risk for coronary heart disease. Analysis of responses by the periodicity of the intervention reveals lower concordance with the recommendations of the USPSTF. The greatest differences were observed for cholesterol in the male clinical scenario, and cervical cytology and the faecal occult blood test in the female scenario.

Considering the male clinical scenario and the USPSTF recommendations, including the periodicity of the interventions, it was possible to calculate a score from 0 to 100 , for each family doctor, where 0 corresponds to no concordance with any of the USPSTF recommendations and 100 corresponds to complete concordance. The mean score was 74 ( $\mathrm{SD}=9$; range 50$100)$. In the study sample, $28 \%$ had a score between 80 and $100,65 \%$ of family physicians had a score between 60 and 79 and $7 \%$ of family physicians had a score between 50 and 59. We did not find significant differences between female and male scores (mean 74 vs 73 ; $\mathrm{p}=0.355$ ) or between family physicians working in urban and family rural settings (mean 74 vs $73 ; \mathrm{p}=0.149$ ). Family physicians younger than 50 years had significantly higher scores than older physicians (mean 77 vs 72; $\mathrm{p}<0.001)$.

For the female clinical scenario, the mean score was 75 ( $\mathrm{SD}=9$; range 42-92). In the study sample, $30 \%$ of physicians had a score between 80 and $100,60 \%$ of family physicians had a score between 60 and 79 and $10 \%$ of family physicians had a score between 42 and 59 . There were no significant differences found between female and male family physicians' scores (mean 75 vs
$74 ; \mathrm{p}=0.397$ ) or between the scores of family physicians younger than 50 years and those 50 or older (mean 75 vs 74; $\mathrm{p}=0.307)$. Family physicians working in an urban setting had significantly higher scores than rural family physicians (mean 75 vs $73 ; \mathrm{p}=0.034$ ).

\section{DISCUSSION}

Portuguese family physicians have high concordance with the USPSTF recommendations in the application of preventive health services. For the male clinical scenario and the female clinical scenario, 93\% and $90 \%$ of Portuguese family physicians, respectively, had a concordance score higher than 60 . Another finding of this study is the coherence between what family physicians say they should perform and what they say they actually perform.

However there appears to be room for improvement in clinical practice. Despite of the high concordance with USPSTF recommendations, concordance scores decrease if we take into account the frequency of the preventive interventions with a defined periodicity.

Regarding cholesterol testing, the USPSTF recommendation is different for male and female patients. Portuguese family physicians do not differ in their performance of this test by the gender of the patient resulting in only $2 \%$ compliance with USPSTF recommendations in the female clinical scenario.

Prostate cancer screening using PSA evaluation and digital rectal examination are two other topics that may 
Table 6 Concordance of family physicians with the USPSTF recommendations

\begin{tabular}{|c|c|c|}
\hline & $\begin{array}{l}\text { Should it be done? } \\
\text { Percentage of physicians who } \\
\text { answered according to the USPSTF } \\
\text { recommendations }\end{array}$ & $\begin{array}{l}\text { Should it be done and how often? } \\
\text { Percentage of physicians who } \\
\text { answered according to the USPSTF } \\
\text { recommendations }\end{array}$ \\
\hline \multicolumn{3}{|l|}{ Male clinical scenario } \\
\hline Cholesterol & 98 & 7 \\
\hline Blood pressure & 100 & 82 \\
\hline FOBT & 84 & 34 \\
\hline PSA & 37 & 37 \\
\hline Inquiry about smoking habits & 100 & $\mathrm{na}^{*}$ \\
\hline If smoker, advice to quit smoking & 98 & na \\
\hline Inquiry about alcohol drinking habits & 100 & na \\
\hline Advice to modify risky drinking habits & 100 & na \\
\hline Body mass index calculation & 100 & na \\
\hline Weight loss advice to overweight patients & 100 & na \\
\hline \multicolumn{3}{|l|}{ Female clinical scenario } \\
\hline Cholesterol & 2 & na \\
\hline Blood pressure & 100 & 78 \\
\hline FOBT & 83 & 27 \\
\hline Mammography & 100 & 82 \\
\hline Cervical cytology & 100 & 29 \\
\hline Inquiry about smoking habits & 100 & na \\
\hline If smoker, advice to quit smoking & 98 & na \\
\hline Inquiry about alcohol drinking habits & 100 & na \\
\hline Advice to modify risky drinking habits & 100 & na \\
\hline Body mass index calculation & 100 & na \\
\hline Weight loss advice to overweight patients & 100 & na \\
\hline
\end{tabular}

be improved in clinical practice. Over $60 \%$ of family physicians in this sample answered they should perform these interventions. These results are significantly higher among family physicians older than 50, which may suggest some inertia in changing routines. Another topic to be improved is the use of chest X-rays for screening, as almost one-third of family physicians thought they should request it in both clinical scenarios and report that they use it in actual practice. This is significantly higher among family physicians over 50 and among those physicians working in rural settings. A high prevalence of pulmonary tuberculosis in Portugal and former practice of ordering chest X-rays as a screening test for that disease might explain this result. The clinical breast examination is another issue to be considered. In light of the fact that this intervention is graded by the USPSTF as a grade I recommendation, which means that the current evidence is insufficient to assess the risk-benefit ratio, the high prevalence of family physicians saying that they should perform this procedure and actually performing this intervention (more than $90 \%$ ) is noted.

As for clinical breast examination, there is little evidence for routine fasting blood glucose evaluation for low-risk patients. However, when the blood pressure is greater than $135 / 80$, this has a grade $\mathrm{B}$ recommendation (see table 7 ). While this preventive intervention has a grade I recommendation, $98 \%$ of the family physicians said that they should perform this intervention on the female and male patients. This result may be interpreted as a sign that diabetes screening is probably being excessive among Portuguese family physicians.

For this study, we considered the recommendations of the USPSTF as the standard because it bases its recommendations on freely accessible, evidence-based systematic reviews, with recognised methodological quality and covers a considerable range of topics. Portugal is in a phase of transition regarding clinical guidelines and recommendations. The Ministry of Health has recently published guidelines covering some topics in preventive medicine. However, many of these guidelines are still in the phase of public discussion and are not based on systematic reviews but rather on experts opinion. For these reasons, we chose the USPSTF recommendations. Exceptions to this are the recommendations of the Portuguese Ministry of Health for the following: breast cancer screening by mammography every 2 years for women 50-69 years old, colorectal cancer screening by a faecal occult blood test every 1-2 years for adults 5074 years old and cervical cancer screening with a cervicovaginal cytology for women between 25 and 60 years every 3 years after two annual normal tests. ${ }^{28}$ Another exception is tetanus immunisation, which is included in the National Vaccination Program. A 10-year interval for 
Table 7 The USPSTF recommendations (according to online version available on 28 March 2013)

\begin{tabular}{|c|c|}
\hline Cholesterol & $\begin{array}{l}\text { Strongly recommends screening men aged } 35 \text { and older for lipid disorders (grade A). Every } \\
5 \text { years } \\
\text { Strongly recommends screening women aged } 45 \text { and older for lipid disorders if they are at } \\
\text { increased risk for coronary heart disease (grade A). Every } 5 \text { years }\end{array}$ \\
\hline Blood pressure & $\begin{array}{l}\text { Recommends screening for high blood pressure in adults aged } 18 \text { and older (grade A). } \\
\text { Every } 2 \text { years }\end{array}$ \\
\hline Fasting glucose & $\begin{array}{l}\text { Recommends screening for type } 2 \text { diabetes in asymptomatic adults with a sustained blood } \\
\text { pressure (either treated or untreated) greater than } 135 / 80 \mathrm{~mm} \mathrm{Hg} \text { (grade B) } \\
\text { Current evidence is insufficient to assess the balance of benefit and harm of screening for } \\
\text { type } 2 \text { diabetes in asymptomatic adults with a blood pressure of } 135 / 80 \mathrm{~mm} \mathrm{Hg} \text { or lower } \\
\text { (grade I) }\end{array}$ \\
\hline FOBT & $\begin{array}{l}\text { Recommends screening for colorectal cancer using FOBT, sigmoidoscopy, or colonoscopy, } \\
\text { in adults, beginning at age } 50 \text { and continuing until age } 75 \text { (grade A). Annual }\end{array}$ \\
\hline Mammography & $\begin{array}{l}\text { Recommends biennial screening mammographies for women aged 50-74 years (grade B). } \\
\text { Every } 2 \text { years }\end{array}$ \\
\hline Clinical breast exam & $\begin{array}{l}\text { Evidence is insufficient to assess the additional benefit and harm of clinical breast } \\
\text { examinations beyond screening mammographies in women } 40 \text { years or older (grade I) }\end{array}$ \\
\hline Cervical cytology & $\begin{array}{l}\text { Recommends screening women 21-65 (Pap smear; grade A) every } 3 \text { years or women } \\
\text { aged } 30-65 \text { (in combo with HPV testing) every } 5 \text { years }\end{array}$ \\
\hline PSA & Recommends against PSA-based screening for prostate cancer (grade D) \\
\hline Chest X-ray & $\begin{array}{l}\text { Evidence is insufficient to recommend for or against screening asymptomatic persons for } \\
\text { lung cancer with low-dose CT, a chest X-ray, sputum cytology or a combination of these } \\
\text { tests (grade I) }\end{array}$ \\
\hline Inquiry about smoking habits & $\begin{array}{l}\text { Recommends that clinicians ask all adults about tobacco use and provide tobacco } \\
\text { cessation interventions for those who use tobacco products (grade A) }\end{array}$ \\
\hline $\begin{array}{l}\text { If smoker, advice to quit } \\
\text { smoking }\end{array}$ & $\begin{array}{l}\text { Recommends that clinicians ask all adults about tobacco use and provide tobacco } \\
\text { cessation interventions for those who use tobacco products (grade A) }\end{array}$ \\
\hline $\begin{array}{l}\text { Inquiry about alcohol drinking } \\
\text { habits }\end{array}$ & $\begin{array}{l}\text { Recommends that clinicians screen adults aged } 18 \text { years or older for alcohol misuse and } \\
\text { provide persons engaged in risky or hazardous drinking with brief behavioural counselling } \\
\text { interventions to reduce alcohol misuse (grade B) }\end{array}$ \\
\hline $\begin{array}{l}\text { Advice to modify risky drinking } \\
\text { habits }\end{array}$ & $\begin{array}{l}\text { Recommends that clinicians screen adults aged } 18 \text { years or older for alcohol misuse and } \\
\text { provide persons engaged in risky or hazardous drinking with brief behavioural counselling } \\
\text { interventions to reduce alcohol misuse (grade B) }\end{array}$ \\
\hline BMI calculation & $\begin{array}{l}\text { Recommends screening all adults for obesity. Clinicians should offer or refer patients with a } \\
\text { BMI of } 30 \mathrm{~kg} / \mathrm{m}^{2} \text { or higher to intensive, multicomponent behavioural interventions (grade B) }\end{array}$ \\
\hline $\begin{array}{l}\text { Weight loss advice to } \\
\text { overweight patients }\end{array}$ & $\begin{array}{l}\text { Recommends screening all adults for obesity. Clinicians should offer or refer patients with a } \\
\text { BMI of } 30 \mathrm{~kg} / \mathrm{m}^{2} \text { or higher to intensive, multicomponent behavioural interventions (grade B) }\end{array}$ \\
\hline Inquiry about physical activity & $\begin{array}{l}\text { Evidence is insufficient to recommend for or against behavioural counselling in primary care } \\
\text { settings to promote physical activity (grade I) }\end{array}$ \\
\hline $\begin{array}{l}\text { Activity advice to sedentary } \\
\text { patients }\end{array}$ & $\begin{array}{l}\text { Evidence is insufficient to recommend for or against behavioural counselling in primary care } \\
\text { settings to promote physical activity (grade I) }\end{array}$ \\
\hline
\end{tabular}

BMI, body mass index; FOBT, faecal occult blood test; HPV, human papillomavirus; PSA, prostate-specific antigen.

each booster dose is recommended. ${ }^{29}$ These recommendations could have influenced our results.

Another factor that may have influenced these results is the impact of recent primary healthcare reform in Portugal. ${ }^{30} 31$ The formation of family health units with contracts that include pay-for-performance targets for preventive services may have had a positive impact in the implementation of preventive services.

Recently published data have evaluated the implementation of some preventive services in the Portuguese National Health Service. These data show that $68 \%$ of women aged 50-69 years have had at least one mammography performed in the past 2 years in family health units with pay for performance contracts. In these family health units, $58 \%$ of women aged 25-64 years had at least one cervical cytology performed in the past 3 years and over $98 \%$ of 2-year-old children have full compliance with the National Vaccination Program. These data provide evidence of external validity for the findings of this study regarding the high rate of compliance of Portuguese family doctors with prevention guidelines. ${ }^{25}$

A recent study has calculated the number of consultations needed in 1 year for a family physician to perform the principal preventive services recommended and to meet the contractual obligations for performance indicators. The authors considered paediatric surveillance, follow-up of pregnant women, diabetic and hypertensive patients, and screening for breast, cervical and colorectal cancer, hypertension, dyslipidaemia and obesity. The results showed that 2848.5 consultations/year would be 
needed to carry out those preventive activities if carried out separately or 2008.9 consultations/year if multiple activities were carried out in the same consultation. The authors concluded that the performance of preventive activities and the achievement of the performance indicators by Portuguese family doctors requires a considerable amount of time and may limit the availability of family physician to take care of sick people. ${ }^{32}$ This perception of a time barrier may explain the differences between the high compliance found in this study, the theoretical situation and the lower figures observed in the reality of daily practice. The study of Pinto et al provides compelling evidence that current demands for preventive activities in primary care are excessive.

Comparing our results with a similar study of European family physicians, ${ }^{13}$ we found a higher compliance with recommendations among Portuguese family physicians regarding what they say they do and should do. This raises concerns about excessive preventive interventions. For cholesterol testing, $99 \%$ of the family physicians in the male and female clinical scenario said that they perform this evaluation. Of those, $99 \%$ and $98 \%$ said that they perform it periodically in the male and female clinical scenarios, respectively, with a median periodicity of 12 months (table 5 ). We obtained similar results for blood pressure measurement and fasting blood glucose evaluation. These are signs that too much medicine is being offered to asymptomatic patients.

When the new Ministry of Health prevention guidelines are published, it will be interesting to replicate this study using the official Portuguese recommendations instead of the USPSTF recommendations.

Our study has some limitations. In order to select a representative sample of the Portuguese family physicians working in the Portuguese National Health Service without a database of family physicians, we had to implement a stratified cluster sampling design. This may have introduced a sampling bias. However, the high response rate obtained $(95.7 \%)$ may have minimised this bias.

Another limitation of this study is the number of preventive interventions that were included in the questionnaire. It would have been interesting to study other medical interventions, for example, other imaging exams, endoscopic exams or serum tumour markers. We did not include more interventions because doing so would have extended the duration of the interviews with the risk of lowering the response rate.

In our study, we presented two clinical scenarios to family physicians and asked them about the preventive interventions they theoretically perform and those they actually perform. This may be influenced by a self-report bias or social desirability. Responses may have been given according to what the participant suspects the researcher wants to hear. We did not validate our findings with clinical records to assess how family physicians are actually performing preventive interventions. Additional real-world research is necessary to assess this. This is needed due to the evidence and growing concern about harm associated with overtesting, overdiagnosing and overtreating. ${ }^{21} 22$ 33-35

Despite the limitations of our study, we believe that these results contribute to an understanding of the way prevention is being applied in Portuguese primary healthcare services. We have obtained positive indications showing good compliance with scientific evidence, but here are also concerns about the excessive use of some medical interventions.

Contributors CMdSM had the original idea of the study, designed the questionnaire and made the quality control during the data collection, drafted and revised the paper. He is guarantor. LFRdA has designed the sampling methodology, contributed to the questionnaire design and revised the paper. CMNdCS planned, supervised and has performed the statistical data analysis, contributed to the paper draft and revised the paper. LMBS, PAAPS,

MLGDdC, AMRdCP and AAOPH contributed to the questionnaire design and revised the paper.

Funding The authors have received a financial support of $€ 15000$ from the AstraZeneca Portugal Foundation 2010 programme for support of research.

Competing interests None.

Ethics approval Portuguese Northern Regional Health Administration Ethics Committee for Health.

Provenance and peer review Not commissioned; externally peer reviewed.

Data sharing statement No additional data are available.

Open Access This is an Open Access article distributed in accordance with the Creative Commons Attribution Non Commercial (CC BY-NC 4.0) license, which permits others to distribute, remix, adapt, build upon this work noncommercially, and license their derivative works on different terms, provided the original work is properly cited and the use is non-commercial. See: http:// creativecommons.org/licenses/by-nc/4.0/

\section{REFERENCES}

1. International Epidemiological Association. A dictionary of epidemiology. 4th edn. New York, NY: Oxford University Press, 2001.

2. Beck LH. Periodic health examination and screening tests in adults. Hosp Pract 1999;34:117-18, 121-2, 124-6.

3. Frame PS, Carlson SJ. A critical review of periodic health screening using specific screening criteria. Part 1: selected diseases of respiratory, cardiovascular, and central nervous systems. J Fam Pract 1975;2:29-36.

4. Breslow L, Somers A. The lifetime health-monitoring program. A practical approach to preventive medicine. $N$ Engl J Med 1977;296:601-8.

5. Canadian Task Force on the Periodic Health Examination. The periodic health examination. CMAJ 1979;121:1193-254.

6. U.S. Preventive Services Task Force. About the USPSTF. http:// www.uspreventiveservicestaskforce.org/about.htm (accessed $28 \mathrm{Mar}$ 2013).

7. United States Preventive Services Task Force, ed. Guide to clinical preventive services. 2nd edn. Washington, DC: US Department of Health and Human Services, 1996.

8. Evidence-Based Medicine Working Group. Evidence-based medicine. A new approach to teaching the practice of medicine. JAMA 1992;268:2420-5.

9. Canadian Task Force on the Periodic Health Examination, Canada The Canadian guide to clinical preventive health care. Ottawa: Health Canada, 1994.

10. Royal Australian College of General Practitioners. Guidelines for preventive activities in general practice. South Melbourne, VIC: Royal Australian College of General Practitioners, 2005.

11. Pérula de Torres LA, Alonso Arias S, Bauzà Nicolai K, et al. Opinions of health professionals on the impact of the Preventive Activities and Health Promotion Program (PAPPS). Atencion Primaria Soc Española Med Fam Comunitaria 2007;39(Suppl 3):5-14.

12. Straus S. Evidence-based medicine: how to practice and teach EBM. 3rd edn. New York, NY: Elsevier/Churchill Livingstone, 2005. 
13. Brotons $\mathrm{C}$, Björkelund $\mathrm{C}$, Bulc $\mathrm{M}$, et al. Prevention and health promotion in clinical practice: the views of general practitioners in Europe. Prev Med 2005;40:595-601.

14. Douketis JD. Incorporating preventive care recommendations into clinical practice: how do we bridge the gap? CMAJ 1999;160:1171-2.

15. Cabana MD, Rand CS, Powe NR, et al. Why don't physicians follow clinical practice guidelines? A framework for improvement. JAMA 1999;282:1458-65.

16. Yarnall KSH, Pollak KI, Østbye T, et al. Primary care: is there enough time for prevention? Am J Public Health 2003;93:635-41.

17. Kloppe P, Brotons C, Anton JJ, et al. [Preventive care and health promotion in primary care: comparison between the views of Spanish and European doctors]. Atencion Primaria Soc Española Med Fam Comunitaria 2005;36:144-51.

18. Merenstein D, Daumit GL, Powe NR. Use and costs of nonrecommended tests during routine preventive health exams. Am J Prev Med 2006;30:521-7.

19. Allan GM, Innes GD. Do family physicians know the costs of medical care? Survey in British Columbia. Can Fam Physician 2004:50:263-70.

20. Allan GM, Lexchin J. Physician awareness of diagnostic and nondrug therapeutic costs: a systematic review. Int J Technol Assess Health Care 2008;24:158-65.

21. Moynihan R, Doust J, Henry D. Preventing overdiagnosis: how to stop harming the healthy. BMJ 2012;344:e3502.

22. Gérvas J, Starfield B, Heath I. Is clinical prevention better than cure? Lancet 2008;372:1997-9.

23. Heath I. Who needs health care-the well or the sick? BMJ 2005;330:954-6.

24. Kalager M, Adami $\mathrm{H}-\mathrm{O}$, Bretthauer $\mathrm{M}$, et al. Overdiagnosis of invasive breast cancer due to mammography screening: results from the Norwegian screening program. Ann Intern Med 2012;156:491-9.
25. Administração Central do sistema de Saúde, IP. Family health units: 2010 activity (Unidades de Saúde Familiar: actividade realizada em 2010). 2011.

26. PORDATA-Médicos por especialidade. http://www.pordata.pt/ Portugal/Ambiente+de+Consulta/Tabela (accessed 14 Jun 2013).

27. Lohr SL. Sampling: design and analysis. Pacific Grove, CA: Duxbury Press, 1999.

28. Ministério da Saúde. National Plan for Prevention and Control of Oncological Diseases 2007/2010.

29. Vaccine Schedule. http://vaccine-schedule.ecdc.europa.eu/Pages/ Scheduler.aspx (accessed 16 Sept 2013)

30. Pisco L. Primary healthcare reform in Portugal on two fronts: autonomous family healthcare units and management of groupings of health centers (Reforma da Atenção Primária em Portugal em duplo movimento: unidades assistenciais autónomas de saúde familiar e gestão em agrupamentos de Centros de Saúde). Ciênc Saúde Coletiva 2011:16:2841-52.

31. Rocha $P$ de $M$, de Sá $A B$. Family health reform in portugal: analysis of its implementation (Reforma da Saúde Familiar em Portugal: avaliação da implantacão). Ciênc Saúde Coletiva 2011;16:2853-63.

32. Pinto D, Corte-Real S, Nunes J. Preventive activities and performance indicators-how much time is left? (Actividades preventivas e indicadores: quanto tempo sobra?). Rev Port Clin Geral 26:455-64.

33. Bleyer A, Welch HG. Effect of three decades of screening mammography on breast-cancer incidence. $N$ Engl J Med 2012;367:1998-2005.

34. Welch HG. Overdiagnosed: making people sick in the pursuit of health. Boston, MA: Beacon Press, 2011.

35. Heleno B, Thomsen MF, Rodrigues DS, et al. Quantification of harms in cancer screening trials: literature review. BMJ 2013;347: f5334. 